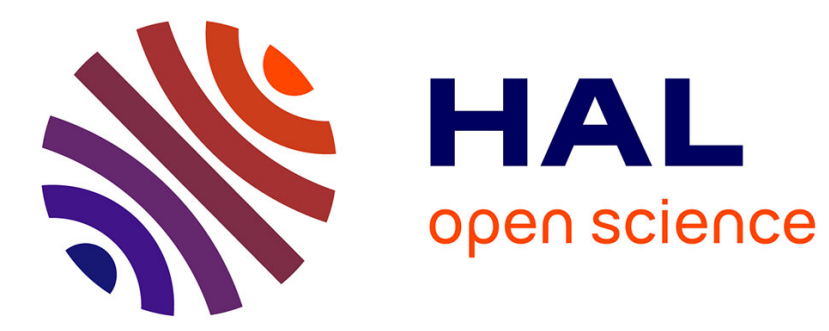

\title{
Field extension inside guided-mode-resonance filters under a focused beam
}

Antoine Bierret, Grégory Vincent, Julien Jaeck, Jean-Luc Pelouard, Riad Haïdar, Fabrice Pardo

\section{- To cite this version:}

Antoine Bierret, Grégory Vincent, Julien Jaeck, Jean-Luc Pelouard, Riad Haïdar, et al.. Field extension inside guided-mode-resonance filters under a focused beam. Optics Letters, 2017, 42 (20), page 4187-4190. 10.1364/OL.42.004187 . hal-01712316

\section{HAL Id: hal-01712316 https://hal.science/hal-01712316}

Submitted on 19 Feb 2018

HAL is a multi-disciplinary open access archive for the deposit and dissemination of scientific research documents, whether they are published or not. The documents may come from teaching and research institutions in France or abroad, or from public or private research centers.
L'archive ouverte pluridisciplinaire HAL, est destinée au dépôt et à la diffusion de documents scientifiques de niveau recherche, publiés ou non, émanant des établissements d'enseignement et de recherche français ou étrangers, des laboratoires publics ou privés. 


\title{
Field extension inside guided-mode-resonance filters under a focused beam
}

\author{
Antoine Bierret ${ }^{1,2}$, Grégory Vincent ${ }^{1}$, Julien Jaeck ${ }^{1}$, JeAn-Luc Pelouard ${ }^{2}$, Riad Haïdar ${ }^{1}$, \\ AND FABRICE PARDO2,* \\ ${ }^{1}$ ONERA - The French Aerospace Lab, Chemin de la Hunière, BP 80100, F-91123 Palaiseau, France \\ ${ }^{2}$ Centre de Nanosciences et Nanotechnologies - CNRS, Route de Nozay, F-91460 Marcoussis, France \\ ${ }^{*}$ Corresponding author: fabrice.pardo@c2n.upsaclay.fr
}

Compiled September 18, 2017

\begin{abstract}
We present a theoretical study of mid-infrared guided mode resonance spectral filters made of two subwavelength metallic gratings and a dielectric waveguide, under a focused beam with a finite spot size. Study shows that, at the resonant wavelength, the lateral extension of the electromagnetic field in the waveguide is close to the width of the beam. We compare the performance of filters using gratings with a one-slit pattern and gratings with a two-slit pattern and we show that the latter gratings (biatom gratings) provide a higher transmission and a better limitation of field extension, due to an improved angular acceptance. These results open new perspectives for pixel-sized infrared filters. @ 2017 Optical Society of America
\end{abstract}

OCIS codes: (130.7408) Wavelength filtering devices; (050.6624) Subwavelength structures; (230.5750) Resonators; (130.3060) Infrared

http://dx.doi.org/10.1364/ao.XX.XXXXXX

Spectral filtering in the infrared wavelength range can be achieved through resonant sub-wavelength periodic structures [1-3]. These structures have a limited number of layers, which is technological advantage as compared to standard multilayer devices like Bragg filters. This makes them particularly suited for the realization of mosaic of reduced-size filters, to be integrated into imaging systems [4]. However, the compatibility of sub-wavelength gratings filters with dimensions as small as the actual pixel size of infrared detectors still needs to be demonstrated. Most of the time, components are studied under plane wave illumination, possibly for variable incidence angles, and the maximum of transmission can be theoretically almost perfect, depending on the use of lossy [5] or lossless materials [6, 7]. For practical infrared imaging systems, it is no longer possible to consider that incoming light is a plane wave but rather a focused beam with a limited spot size.

We consider a component that belongs to the family of guided mode resonance filters (GMR filters), initially proposed by Magnusson and Wang [1], and then derived in numerous studies[8]. Such a component is based on the coupling of the free-space incoming and outgoing light with a guided mode inside a dielectric layer. We will focus on the study of a free-standing metallo-dielectric GMR filter, made of a dielectric waveguide sandwiched by symmetric metallic gratings deposited on each sides, to achieve spectral filtering in the midwave infrared $(3-5 \mu \mathrm{m})$ because they lead to better angular tolerances than full dielectric GMR filters [9]. The coupling is ensured by the two sub-wavelength gratings and this device leads to a spectrally selective resonant transmission [3]. The rejection of the component is rather high thanks to a perfect extinction mechanism at high wavelengths, as demonstrated by Estruch [10] and Tardieu [11]. More precisely in this paper, we consider on the one hand gratings with a one-slit pattern, called a monoatom filter, and on the other hand gratings with a two-slit pattern called a biatom filter [9, 12]. As described in reference [12], the biatom structure uses a second slit to tune the resonant wavelength without changing the period of the grating. By choosing a resonant wavelength under normal incidence close to the crossing wavelength of the dispersion bands of the grating, we obtain a flatter transmission band, which results on a maximized angular acceptance. This acceptance plays a major role when used under focused beams as the angular independence is a necessary condition for focused light to be efficiently coupled into the waveguide. However, the narrow extent of the electro-magnetic field inside the waveguide, which is essential to create pixel-sized filters, is not definitely ensured by the angular independence of the filter. Several studies have been lead on dielectric-only GMR filters under focused beams in the literature [13-15]. However, the beams were always very loosely focused.

In this letter, we investigate through simulations the optical properties of guided mode resonance filters under a focused illumination, and we show that the lateral extension of the electromagnetic field in the waveguide at resonant wavelength is close to the width of the incident beam.

In order to address the specific case of GMR filters under a focused beam, we first need to design such filters with suitable spectral and angular characteristics under a plane wave illumination. Optical properties of the filters are computed using rigorous coupled-wave analysis (RCWA) [16]. The simulations are carried for 2-dimensional structures, meaning that the grating is periodic along $\mathrm{x}$-axis and invariant along $\mathrm{y}$-axis. This config- 
(a)

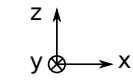

)

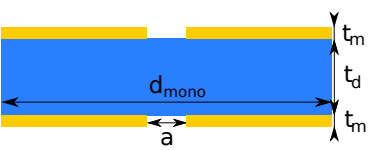

(c) 1

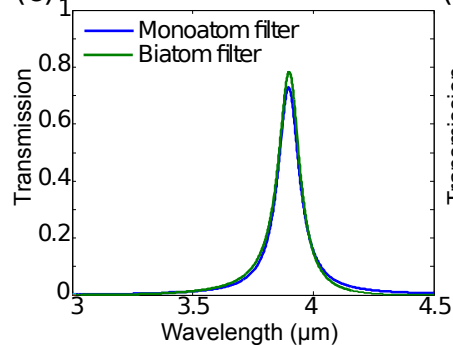

(b)

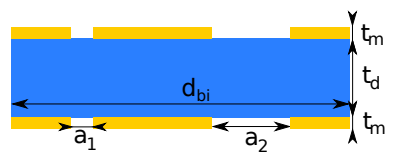

(d)

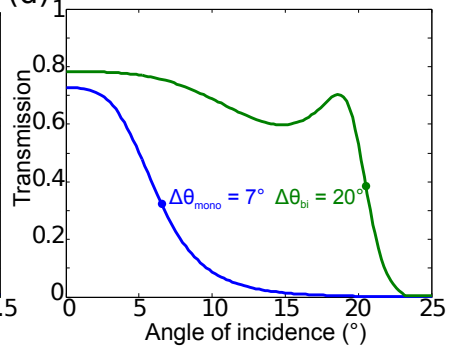

Fig. 1. a) Cross-section of a single pattern of a monoatom filter. b) Cross-section of a single pattern of a biatom filter. c) Spectra corresponding to infinite-sized filters of patterns described in 1.a) and 1.b) with the parameters: $d_{\text {mono }}=2.075 \mu \mathrm{m}$, $a_{\text {mono }}=0.16 \mu \mathrm{m}, d_{b i}=2.8 \mu \mathrm{m}, a_{1, b i}=0.19 \mu \mathrm{m}, a_{2, b i}=$ $0.67 \mu \mathrm{m}, t_{m}=100 \mathrm{~nm}, t_{d}=650 \mathrm{~nm}$ illuminated by a TM plane wave. d) Evolution of the transmission with the angle of incidence of the plane wave at resonant wavelength $\lambda=3.905 \mu \mathrm{m}$.

uration was chosen to provide a good insight on the properties of our components while maintaining a short computation time. Because we consider metallo-dielectric GMR made of infinitely long slits, the simulations only take into account transversemagnetic (TM) polarized light, which means that magnetic field is parallel to the slits (y-axis). Monoatom and biatom filter geometries are respectively described in figure 1.a) and figure 1.b). Chosen dimensions are as follows, for monoatom filter: period is $d_{\text {mono }}=2.075 \mu \mathrm{m}$ and slits width is $a_{\text {mono }}=0.16 \mu \mathrm{m}$; for biatom filter: $d_{b i}=2.8 \mu \mathrm{m}, a_{1, b i}=0.19 \mu \mathrm{m}, a_{2, b i}=0.67 \mu \mathrm{m}$. The distance between the center of each slit in the bi-atom patern is $\frac{d}{2}$. Thicknesses are $t_{m}=100 \mathrm{~nm}, t_{d}=650 \mathrm{~nm}$ for both filters. Dielectric layer is made of silicon nitride, whose refractive index is taken as $n_{S i N x}=2.15$. The refractive index of gold is given by a Drude model: $\epsilon_{m}(\lambda)=1-\left(\left(\frac{\lambda_{p}}{\lambda}+i \gamma\right) \frac{\lambda_{p}}{\lambda}\right)^{-1}$ with $\lambda_{p}=159 \mathrm{~nm}$ and $\gamma=0.0048$ matching recent experimental results $[17,18]$. Figure 1.c) shows the transmission spectra for both filters. The dimensions of monoatom and biatom filters were optimized to obtain similar spectral shapes, with resonant wavelength $\lambda_{\text {mono }}=\lambda_{b i}=3.905 \mu \mathrm{m}$, and spectral full width at half maximum $F W H M_{\text {mono }}=F W H M_{b i}=110 \mathrm{~nm}$. The transmissions at the resonant wavelengths could not be exactly matched with these conditions and are respectively $T_{\max , \operatorname{mono}}=72.7 \%$ and $T_{\max , b i}=78.3 \%$. Figure 1.d) gives the evolution of the transmission when the angle of incidence of the plane wave increases for both filters at $\lambda=3.905 \mu \mathrm{m}$. It reveals that, as shown by Sakat [9], the biatom filter offers a much larger angular acceptance, $\Delta \theta$, defined as the angle where transmission reaches half of the normal incidence value: $\Delta \theta_{b i}=20^{\circ}$ for biatom component and $\Delta \theta_{\text {mono }}=7^{\circ}$ for monoatom component.

Now that the opto-geometrical parameters of the components have been properly defined, we can then study the response of the filters to a focused beam. Since our simulations are performed with RCWA software, the focused beam can be described as a sum of plane waves, by means of a de- composition in Fourier series as proposed by Chevalier [19]. Depending on the beam focus, the Fourier series can be truncated of its highest orders because of their low magnitude. This method allows choosing the shape and size of the beam at will and reducing the computation time. In accordance with the 1-dimensional geometry of the grating, the incoming beam is thus invariant along the $y$-axis. Along the $\mathrm{x}$-axis we consider a periodic repetition of the beam, since we use a RCWA algorithm dedicated to the study of periodic structures: the incoming wavefront is here repeated every $112 \mu \mathrm{m}$. This value is way higher than the period of the gratings and way higher than the width of the spots. To ensure independent responses to each beam, the pattern of the amplitude of the beam is null except inside the interval $\left[0 ; 2.466 \mathrm{w}_{0}\right]$ where it is defined as an approximated Blackman equation [20]:

$$
\mathrm{B}(x)=\frac{1-a}{2}-\frac{1}{2} \cos \left(\frac{2 \pi x}{2.466 \mathrm{w}_{0}}\right)+\frac{a}{2} \cos \left(\frac{4 \pi x}{2.466 \mathrm{w}_{0}}\right)
$$

where $x \in\left[0 ; 2.466 \mathrm{w}_{0}\right]$ and $\mathrm{w}_{0}$ is the desired FWHM, with the usual parameter $a=0.16$. The Blackman beam shape was chosen because of the quickly decreasing magnitudes of the terms of its Fourier decomposition. High-order terms, which correspond to the most tilted plane waves, are truncated when their magnitude is a thousand times lower than the zero-order magnitude. This introduces a maximum angle for the plane waves taken into account in the computation. This angle, called $\theta_{a p}$, is the angular aperture of our beam (see figure 2.b). The simulation is carried for each plane wave on a single period of the grating, and then the results can be propagated to any number of periods. This is faster than the direct computation of an incoming plane wave on a large number of periods. Last, the response of the component to the focused beam is a sum of all the previous responses, weighted by the Fourier coefficients of each plane wave.

At first, we consider a Blackman function with a spatial FWHM of $\mathrm{w}_{0}=9 \mu \mathrm{m}$, meaning that the full width at $10 \%$ of the maximum (spot size) is $16 \mu \mathrm{m}$. In this case, the angular aperture of the beam is $\theta_{a p}=20^{\circ}$ which is consistent with the angular acceptance of the biatom filter (see fig.1.d).

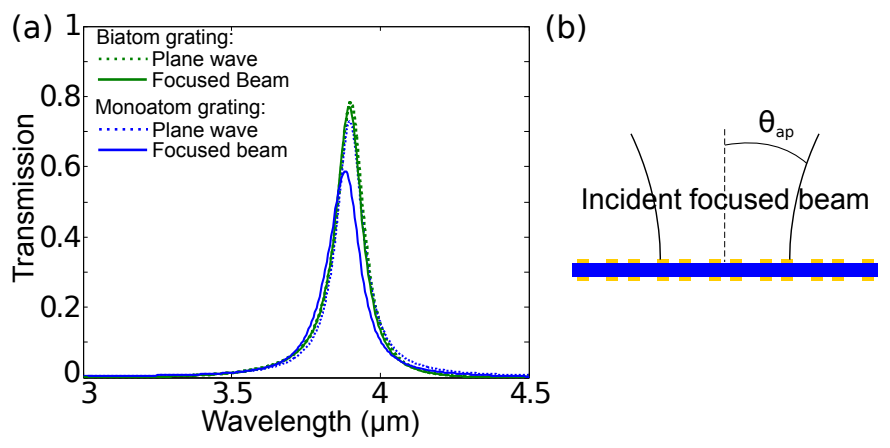

Fig. 2. a) Spectra of the mono-atom and bi-atom Dual Metallic Gratings described in figure 1, under a plane wave illumination and for a focused beam. Plane wave and focused beam spectra are overlapping for the biatom filter. b) Schematic view of the periodic structure and the focused beam. The angle $\theta_{a p}$ corresponds to the angular aperture of the beam.

In figure 2.a, we show the spectra for a biatom (green lines) and a monoatom (blue lines) filter either under focused beam (plain lines) or under normally-incident plane wave (dotted 
lines). Resonance is barely modified for biatom structuration under focused beam illumination with respect to the resonance under plane wave illumination. On the contrary, under focused beam for monoatom structuration the resonant wavelength is slightly blue-shifted to $\lambda_{\text {mono }}=3.885 \mu \mathrm{m}$ and the maximum of transmission drops to $T_{\max }=62 \%$. These results are directly linked to the angular behavior of the filters: with an angular aperture of $\theta_{a p}=20^{\circ}$, the beam remains close to the angular acceptance of the biatom filter, $\Delta \theta_{b i}$, but is well above that of the monoatom filter, $\Delta \theta_{\text {mono }}$. In this last case, it leads to a weaker coupling of the beam with the waveguide.

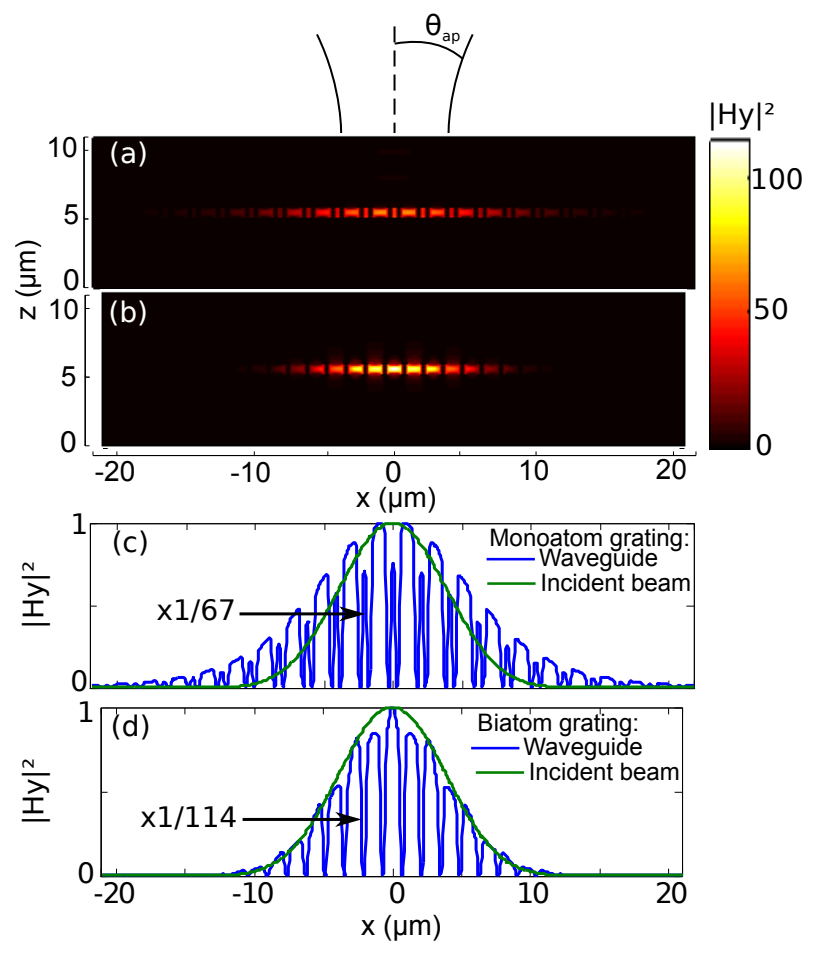

Fig. 3. a) and b) Cross section of the magnetic field intensity in a monoatom (a) or biatom (b) filter under a monochromatic focused beam of waist $\mathrm{w}_{0}=9 \mu \mathrm{m}$ and wavelength $3.885 \mu \mathrm{m}$ (a) or $3.905 \mu \mathrm{m}$ (b). c) and d) In blue: $\left|\mathrm{H}_{\mathrm{y}}\right|^{2}$ along the $\mathrm{x}$-axis for a monoatom (c) or biatom (d) filter. Incident beam is represented in green. Curves are normalized at $x=0$.

On figure 3 we represent the magnetic field intensity in the filters at their respective resonant wavelengths $\lambda_{\text {mono }}=$ $3.885 \mu \mathrm{m}$ and $\lambda_{b i}=3.905 \mu \mathrm{m}$, under the focused beam described previously. On figures 3.a (monoatom filter) and 3.b (biatom filter) we show cross-sections of the intensity inside the waveguide in linear color level. In 3.c and 3.d, we give another representation of the same magnetic field intensities with plots (blue lines) along a horizontal cut in the middle of the waveguide.These intensities were normalized in order to compare their lateral extension with that of the intensity of the incident beam (green lines), because the maximum intensity inside the waveguide is way higher than in the incoming beam (67 times for a monoatom filter and 114 times for a biatom filter).

It is noteworthy that the field confinement is better in a biatom filter than for a monoatom. If $\mathrm{w}_{0}=9 \mu \mathrm{m}$ for the incident beam, then the field extension (spatial FWHM of the envelope of the magnetic intensity) inside the waveguide for both filters are $\mathrm{w}_{\mathrm{bi}}=9.6 \mu \mathrm{m}$ and $\mathrm{w}_{\mathrm{mono}}=13.0 \mu \mathrm{m}$.
Similar calculations have been led for various values of $\mathrm{w}_{0}$, ranging from $5 \mu \mathrm{m}$ to $30 \mu \mathrm{m}$, at resonant wavelength. The values of $\mathrm{w}_{\mathrm{bi}}$ and $\mathrm{w}_{\text {mono }}$ have been calculated for each beam, and are plotted on figure 4.a), respectively in green and blue, while $\mathrm{w}_{0}$ the spatial FWHM of the incident beam is plotted in red. Normalized incoming beam intensity is represented in inset, for two different values of $\mathrm{w}_{0}: 9 \mu \mathrm{m}$ (value considered in figures 2 and 3) and $25 \mu \mathrm{m}$.
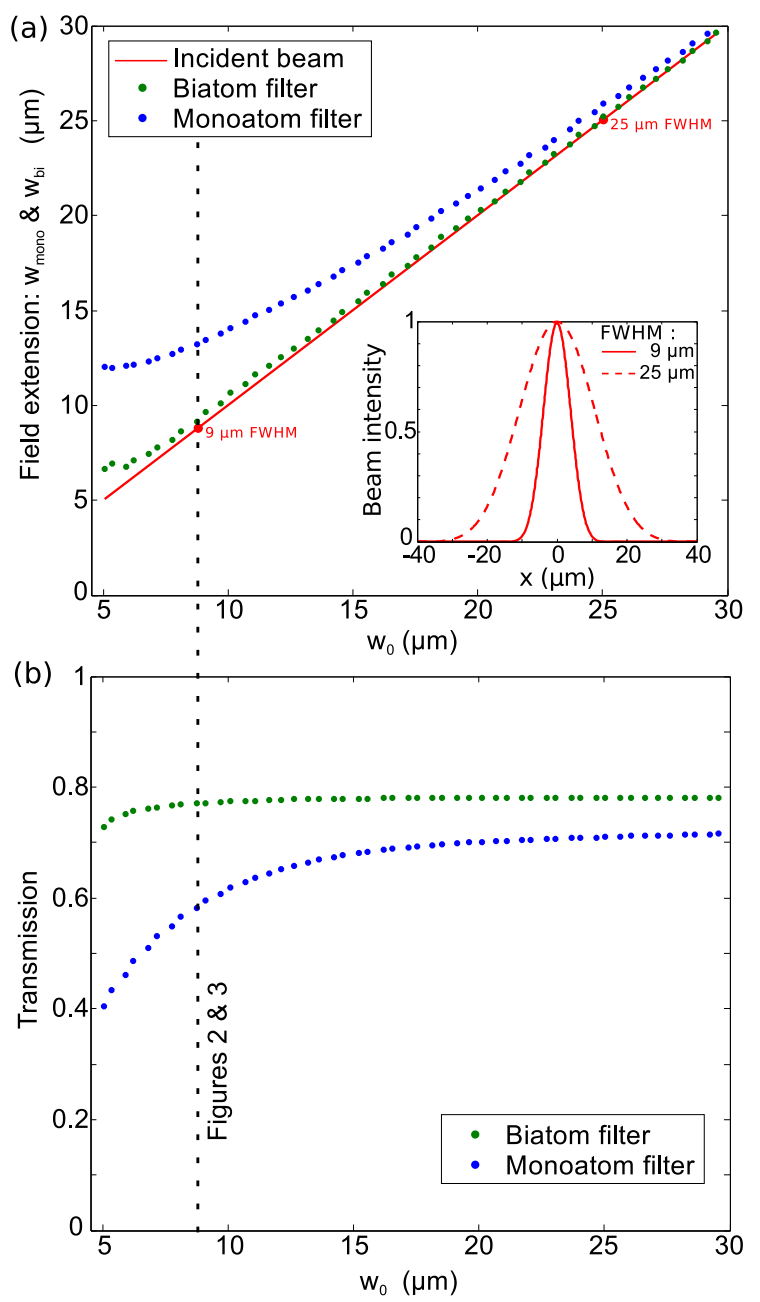

Fig. 4. a) Magnetic field extension inside the waveguide at the resonant wavelength for the monoatom (blue) and biatom (green) filters described in figure 1, under focused beam illumination, as a function of $\mathrm{w}_{0}$. The inset shows the shape of the incoming beam at $\mathrm{w}_{0}=9 \mu \mathrm{m}$ and $25 \mu \mathrm{m}$ b) Transmission maximum of filters.

For $\mathrm{w}_{0}=5 \mu \mathrm{m}$, the field extension for the two filters are $\mathrm{w}_{\text {mono }}=11.5 \mu \mathrm{m}$ and $\mathrm{w}_{\mathrm{bi}}=6.3 \mu \mathrm{m}$. Both field extensions converge asymptotically towards $\mathrm{w}_{0}$ as the beam widens. While the responses of both filters exhibit a hyperbolic behavior as a function of $w_{0}$ in the studied range $[5 ; 30] \mu \mathrm{m}$, the monoatom filter exhibits a wider field extension than the biatom. This is due to its lower angular acceptance: when $\theta_{a p}>\Delta \theta$, there is a widening of the field extension inside the waveguide because the the highest orders of the decomposition (corresponding to the most tilted plane waves) are not efficiently coupled into the waveguide. On the contrary, when $\theta_{a p}<\Delta \theta$ every plane wave is coupled into the waveguide and contributes to the interfer- 
ence leading to a limited field extension.

In figure 4.b) we study the spectral properties of the filters by investigating the transmission at the resonant wavelength for various values of $\mathrm{w}_{0}$. For $\mathrm{w}_{0}=5 \mu \mathrm{m}$, the transmissions are $T_{\text {mono }}=40.4 \%$ and $T_{b i}=72.8 \%$. Both transmissions converge towards their respective plane-wave value as the beam widens. Furthermore, the maximum transmission of the biatom filter starts to decrease for a narrower beam than that of the monoatom filter. Indeed, for the same reason that led to widening of the field extension, the transmission only decreases when the aperture of the beam becomes greater than the acceptance of the filter. Consequently, both filters are adequate for loosely focused beam, but biatom filters are more efficient for tighter beams.

In summary, we demonstrated that GMR filters keep their filtering abilities under focused beam. In addition, we have demonstrated that field extension in the waveguide is comparable to the spatial FWHM of the incoming beam, provided that its angular aperture is compatible with the angular acceptance of the filter (this is the reason why the biatom structure should be used preferably for tightly focused beams). The study was lead with an incoming focused beam whose spot size is close to the size of an infrared pixel (roughly $15 \mu \mathrm{m}$ to $30 \mu \mathrm{m}$ ). We showed that for such a small spot size, the magnetic field is contained in the pixel area too. This opens new possibilities for mosaics of pixel-sized infrared spectral filters. Because it overcomes technological limits shown by mosaic of thin-film pixelsized filters [21, 22], subwavelength gratings could be a new technological solution to achieve colored pixels in the infrared, thus leading to multispectral infrared focal plane arrays.

\section{REFERENCES}

1. R. Magnusson and S. S. Wang, Applied Physics Letters 61, 1022 (1992).

2. J. A. Porto, F. J. García-Vidal, and J. B. Pendry, Physical Review Letters 83, 2845 (1999).

3. E. Sakat, G. Vincent, P. Ghenuche, N. Bardou, S. Collin, F. Pardo, J.-L. Pelouard, and R. Haïdar, Optics Letters 36, 3054 (2011).

4. R. Haïdar, G. Vincent, S. Collin, N. Bardou, N. Guérineau, J. Deschamps, and J.-L. Pelouard, Applied Physics Letters 96, 221104 (2010).

5. Y. Ding and R. Magnusson, Optics Express 12, 1885 (2004).

6. S. Collin, G. Vincent, R. Haïdar, N. Bardou, S. Rommeluère, and J.-L. Pelouard, Physical Review Letters 104, 027401 (2010).

7. A.-L. Fehrembach, D. Maystre, and A. Sentenac, JOSA A 19, 1136 (2002).

8. R. Magnusson and Y. H. Ko, "Guided-mode resonance nanophotonics: fundamentals and applications," (2016), vol. 9927, pp. 992702992702-13.

9. E. Sakat, S. Héron, P. Bouchon, G. Vincent, F. Pardo, S. Collin, J.-L. Pelouard, and R. Haïdar, Optics Letters 38, 425 (2013).

10. T. Estruch, J. Jaeck, F. Pardo, S. Derelle, J. Primot, J.-L. Pelouard, and R. Haidar, Optics Letters 36, 3160 (2011).

11. C. Tardieu, T. Estruch, G. Vincent, J. Jaeck, N. Bardou, S. Collin, and R. Haïdar, Optics Letters 40, 661 (2015).

12. A. Sentenac and A.-L. Fehrembach, JOSA A 22, 475 (2005).

13. J. M. Bendickson, E. N. Glytsis, T. K. Gaylord, and D. L. Brundrett, JOSA A 18, 1912 (2001).

14. G. Niederer, H. P. Herzig, J. Shamir, H. Thiele, M. Schnieper, and C. Zschokke, Applied Optics 43, 1683 (2004).

15. A.-L. Fehrembach, A. Talneau, O. Boyko, F. Lemarchand, and A. Sentenac, Optics letters 32, 2269 (2007).

16. J. Hugonin and P. Lalanne (2005).

17. C. Koechlin, P. Bouchon, F. Pardo, J. Jaeck, X. Lafosse, J.-L. Pelouard, and R. Haïdar, Applied Physics Letters 99, 241104 (2011).
18. R. L. Olmon, B. Slovick, T. W. Johnson, D. Shelton, S.-H. Oh, G. D. Boreman, and M. B. Raschke, Physical Review B 86, 235147 (2012).

19. P. Chevalier, P. Bouchon, F. Pardo, and R. Haïdar, JOSA A 31, 1692 (2014).

20. A. Nuttall, IEEE Transactions on Acoustics, Speech, and Signal Processing 29, 84 (1981).

21. M. Oussalah, F. Pradal, B. Portier, D. Mouricaud, H. Sik, J. Fleury, and P. Laprat, "Multispectral thin film coating on infrared detector," (2015), vol. 9627, pp. 96271W-96271W-10.

22. B. Geelen, N. Tack, and A. Lambrechts, "A compact snapshot multispectral imager with a monolithically integrated per-pixel filter mosaic," in "Spie Moems-Mems," (International Society for Optics and Photonics, 2014), pp. 89740L-89740L. 


\section{FULL REFERENCES}

1. R. Magnusson and S. S. Wang, "New principle for optical filters," Applied Physics Letters 61, 1022 (1992).

2. J. A. Porto, F. J. García-Vidal, and J. B. Pendry, "Transmission Resonances on Metallic Gratings with Very Narrow Slits," Physical Review Letters 83, 2845-2848 (1999).

3. E. Sakat, G. Vincent, P. Ghenuche, N. Bardou, S. Collin, F. Pardo, J.-L. Pelouard, and R. Haïdar, "Guided mode resonance in subwavelength metallodielectric free-standing grating for bandpass filtering," Optics Letters 36, 3054-3056 (2011).

4. R. Haïdar, G. Vincent, S. Collin, N. Bardou, N. Guérineau, J. Deschamps, and J.-L. Pelouard, "Free-standing subwavelength metallic gratings for snapshot multispectral imaging," Applied Physics Letters 96, 221104 (2010).

5. Y. Ding and R. Magnusson, "Use of nondegenerate resonant leaky modes to fashion diverse optical spectra," Optics Express 12, 1885 (2004).

6. S. Collin, G. Vincent, R. Haïdar, N. Bardou, S. Rommeluère, and J.L. Pelouard, "Nearly Perfect Fano Transmission Resonances through Nanoslits Drilled in a Metallic Membrane," Physical Review Letters 104, 027401 (2010).

7. A.-L. Fehrembach, D. Maystre, and A. Sentenac, "Phenomenological theory of filtering by resonant dielectric gratings," JOSA A 19, 11361144 (2002).

8. R. Magnusson and Y. H. Ko, "Guided-mode resonance nanophotonics: fundamentals and applications," (2016), vol. 9927, pp. 992702992702-13.

9. E. Sakat, S. Héron, P. Bouchon, G. Vincent, F. Pardo, S. Collin, J.L. Pelouard, and R. Haïdar, "Metal-dielectric bi-atomic structure for angular-tolerant spectral filtering," Optics Letters 38, 425-427 (2013).

10. T. Estruch, J. Jaeck, F. Pardo, S. Derelle, J. Primot, J.-L. Pelouard, and R. Haidar, "Perfect extinction in subwavelength dual metallic transmitting gratings," Optics Letters 36, 3160 (2011).

11. C. Tardieu, T. Estruch, G. Vincent, J. Jaeck, N. Bardou, S. Collin, and R. Haïdar, "Extraordinary optical extinctions through dual metallic gratings," Optics Letters 40, 661 (2015).

12. A. Sentenac and A.-L. Fehrembach, "Angular tolerant resonant grating filters under oblique incidence," JOSA A 22, 475-480 (2005).

13. J. M. Bendickson, E. N. Glytsis, T. K. Gaylord, and D. L. Brundrett, "Guided-mode resonant subwavelength gratings: effects of finite beams and finite gratings," JOSA A 18, 1912-1928 (2001).

14. G. Niederer, H. P. Herzig, J. Shamir, H. Thiele, M. Schnieper, and C. Zschokke, "Tunable, oblique incidence resonant grating filter for telecommunications," Applied Optics 43, 1683-1694 (2004).

15. A.-L. Fehrembach, A. Talneau, O. Boyko, F. Lemarchand, and A. Sentenac, "Experimental demonstration of a narrowband, angular tolerant, polarization independent, doubly periodic resonant grating filter," Optics letters 32, 2269-2271 (2007).

16. J. Hugonin and P. Lalanne, "Reticolo software for grating analysis," (2005).

17. C. Koechlin, P. Bouchon, F. Pardo, J. Jaeck, X. Lafosse, J.-L. Pelouard, and R. Haïdar, "Total routing and absorption of photons in dual color plasmonic antennas," Applied Physics Letters 99, 241104 (2011).

18. R. L. Olmon, B. Slovick, T. W. Johnson, D. Shelton, S.-H. Oh, G. D. Boreman, and M. B. Raschke, "Optical dielectric function of gold," Physical Review B 86, 235147 (2012).

19. P. Chevalier, P. Bouchon, F. Pardo, and R. Haïdar, "Electromagnetic modelization of spherical focusing on a one-dimensional grating thanks to a conical B-spline modal method," JOSA A 31, 1692-1697 (2014)

20. A. Nuttall, "Some windows with very good sidelobe behavior," IEEE Transactions on Acoustics, Speech, and Signal Processing 29, 84-91 (1981).

21. M. Oussalah, F. Pradal, B. Portier, D. Mouricaud, H. Sik, J. Fleury, and P. Laprat, "Multispectral thin film coating on infrared detector," (2015), vol. 9627, pp. 96271W-96271W-10.

22. B. Geelen, N. Tack, and A. Lambrechts, "A compact snapshot multispectral imager with a monolithically integrated per-pixel filter mosaic," in "Spie Moems-Mems," (International Society for Optics and Photonics, 2014), pp. 89740L-89740L. 